\title{
Blockade of p75 Neurotrophin Receptor Reverses Irritability and Anxiety-Related Behaviors in a Rat Model of Status Epilepticus
}

\author{
Soraya Mehrabi ${ }^{1}$, Mahyar Janahamdi ${ }^{* 2}$, Mohammad Taghi Joghataie ${ }^{1,4,5^{* *}}$, Mahmood Barati ${ }^{3}$, \\ Mohsen Marzban ${ }^{1}$, Mahmoudreza Hadjighassem ${ }^{1,6}$ and Maryam Farahmandfar ${ }^{1}$ \\ ${ }^{1}$ Department of Neuroscience, School of Advanced Technologies in Medicine, Tehran University of Medical Sciences, \\ Tehran, Iran; ${ }^{2}$ Neuroscience Research Center and Department of Physiology, School of Medicine, Shahid Beheshti \\ University of Medical Sciences, Tehran, Iran; ${ }^{3}$ Department of pharmaceutical biotechnology, School of pharmacy, \\ Shahid Beheshti University of Medical Sciences, Tehran, Iran; ${ }^{4}$ Cellular and Molecular Research Center, \\ Iran University of Medical Sciences, Tehran, Iran; ${ }^{5}$ Department of Neuroscience, Faculty \\ of Advanced Technologies in Medicine, Iran University of Medical Sciences, Tehran, Iran; ${ }^{6}$ Brain and Spinal Cord \\ Injury Research Center, Neuroscience Institute, Tehran University of Medical Sciences, Tehran, Iran
}

Received 1 August 2017; revised 20 September 2017; accepted 25 September 2017

\begin{abstract}
Background: Many recent epidemiological studies have shown that epileptic patients are more likely suffer from depression, anxiety, and irritability. However, the cellular mechanisms of epilepsy-induced psychotic behaviors are not fully elucidated. Neurotrophin receptors have been suggested to be involved in epilepsy and also in psychiatric disorders. Up-regulation of p75NTR expression and activation of p75NTR signalling cascades after the seizure have been shown, but the role of the p75 receptor in epilepsy-induced psychotic behaviors has not been documented so far. Therefore, the present work aimed to investigate the effect of p75 receptor blockade on seizure activity, irritability, and anxiety-like behaviors in a rat model of status epilepticus. Methods: Rats were injected with pilocarpine (350 mg/ kg, i.p.) to induce status epilepticus. Then various behavioral tests were performed after the blockade of p75NTR alone or in combination with p75 antagonist and phenobarbital. Molecular analysis by PCR was performed to investigate the expression of p75 and pro-NGF. Results: Molecular findings indicated a high level of mRNA expression for both p75 receptors and pro-NGF in the epileptic model group. Results also showed that the administration of p75 antagonist alone or in combination with phenobarbital was able to significantly influence the behavioral responses. Furthermore, 20-hours video monitoring showed a decrease in the frequency and duration of seizures in the rat group receiving p75 antagonist. Conclusion: Taken together, the present study suggests that the blockade of the p75 receptor may affect the irritability and anxietyrelated behavior in a rat model of status epilepticus. DOI: 10.22034/ibj.22.4.264
\end{abstract}

Keywords: Anxiety, Pilocarpine, Status epilepticus

Corresponding Author: Mahyar Janahmadi

Neuroscience Research Center and Department of Physiology, School of Medicine, Shahid Beheshti University of Medical Sciences, Tehran, Iran; E-mail: Janahmadi@sbmu.ac.ir

Co-Corresponding Author: Mohammad Taghi Joghataie

Department of Neuroscience, School of Advanced Technologies in Medicine, Tehran University of Medical Sciences, Tehran, Iran and Cellular and Molecular Research Center, Iran University of Medical Sciences, Tehran, Iran

\section{INTRODUCTION}

$\mathrm{E}$ Pilepsy is one of the most common neurological disorders with a prevalence of $1 \%$ in the general population. This disorder is associated with the excessive electrical discharges in the neurons. Studies have shown that the prevalence of psychiatric disorders in patients with epilepsy is more frequent than that in general population ${ }^{[1,2]}$. More than one in four epileptic patients have experienced psychological problems, 
which might need treatment, and more than $10 \%$ of patients in psychiatric hospitals are diagnosed with epilepsy ${ }^{[3]}$. Seizure is related with neurological and behavioral problems such as anxiety, memory impairment, psychosis, and cognitive dysfunction, which affect the quality of life of patients ${ }^{[4-6]}$.

Several lines of evidence have indicated that nerve damage and sclerosis occur in different areas of the brain, especially in the hippocampus of patients with temporal lobe epilepsy (TLE) ${ }^{[7-10]}$. Thus, after the initial damages, this area could be considered as the origin of spontaneous seizures. In addition, since the hippocampus, as a part of the limbic system, plays an important role in learning and memory and mood stability, its destruction can cause behavioral abnormalities such as fear, anxiety, depression, memory impairment, and hyperexcitability ${ }^{[11]}$. In TLE, hyperexcitability and neuronal loss in hippocampus evoke psychiatric problems, such as mood disturbances. On the other hand, hippocampal atrophy and synaptic disturbances, which occur in depression, increase neuronal excitability, thereby leading to $\mathrm{TLE}^{[12]}$. Therefore, epilepsy and neuropsychiatric disorders may have common pathophysiological mechanisms.

The involvement of neurotrophins in several nervous system disorders, including epilepsy and neuropsychiatric disorders, has been reported ${ }^{[13,14]}$. Neurotropic factors have been considered as important candidates for therapeutic intervention against neurological diseases. Considering the important role of these factors in the nervous system, investigation of their signalling pathways and ligand-receptor interactions is essential. One of these signalling pathways is related to the function of p75 neurotrophin receptors, which is a transmembrane receptor for tumor necrosis family of growth factors, including nerve growth factor (NGF), brain-derived neurotrophic factor (BDNF), neurotropic 3 (NT3) and neurotropic 4 $(\mathrm{NT} 4)^{[15,16]}$.

Previous studies have reported that high affinity of pro-neurotrophins to $\mathrm{p} 75$ receptors increases the rate of neuropsychiatric diseases including depression ${ }^{[17]}$. These receptors are widely expressed throughout the brain in embryonic periods. Hippocampal neurones also express p75 receptors in various stages of development ${ }^{[18]}$. Expression of the p75 receptor is increased in the hippocampus after seizures as well as in the forebrain cholinergic neurons following damages due to the excessive excitability of these neurons. In addition to this, re-expression of p75 in the aforementioned cells may be a part of damage-induced plasticity, which will start the mechanism of evolutionary recapitulation in the case of lesions and stressors, leading to the production of pro-NGR in some brain areas where p75-dependent cell death may occur $^{[19-23]}$.

p75 re-expression has been indicated to be a part of a homeostatic program to destroy neurons, axons, and synapses in the degenerated or damaged areas ${ }^{[24]}$. Therefore, it seems quite logical that the p75 signalling pathway can be regarded as a therapeutic target for these conditions and has to be taken into consideration. The reason for this consideration might be that epilepsy comorbidity with the most psychiatric disorders in epileptic patients is struggling with these issues ${ }^{[17,25]}$. This comorbidity has still not been well defined, and the relationship between epilepsy and psychiatric disorders has not been fully determined although some attempts have been made to find a correlation between epilepsy and mental health problems ${ }^{[26]}$. Various animal models have been developed for the study of epilepsy, and among them, pilocarpine-induced epilepsy is one of the most common models in the rodent. In this model of epilepsy, development of spontaneous seizure results in behavioral disturbances, which may take three weeks up to three months after pilocarpine-induced status epilepticus. Investigations performed on the pilocarpine model have reported that epilepsy can be divided into three stages: acute, latent, and chronic $^{[27,28]}$. However in two recent studies, this concept was changed, so that in the first days after induction of seizures, epilepsy was divided into the immature and mature phases, where the onset of aggression and agitation in behavior coincided with the mature phase of seizures ${ }^{[29,30]}$.

The present study, by using molecular and behavioral approaches, aimed to answer two questions: The first one is what would be the behavioral consequences of enhancement of p75 and pro-NGF levels in the animal model of TLE induced by pilocarpine, and the second one is whether p75 receptor blockade can be effective on behavioral changes induced by pilocarpine injection.

\section{MATERIALS AND METHODS}

\section{Animals}

Adult male Wistar rats, provided by Shahid Beheshti University Animal House (Tehran, Iran), were housed under controlled standard conditions (12 h light/dark cycle), with food and water available ad libitum a week before. Rats were divided into three main groups ( $\mathrm{n}=$ 7 rats in each group), including the control group, vehicle-treated group, and pilocarpine-treated group. The pilocarpine-treated group was further subdivided 
into four groups (pilo-treated alone, pilo-treated + p75 antagonist, pilo-treated + p75 antagonist + phenobarbital, and pilo-treated + pheno-barbital; $\mathrm{n}=7$ rats were assigned for each group. The dose of P75 antagonist was chosen based on previous studies ${ }^{[31,32]}$. All experiments were performed in accordance with the animal care and management rules approved by the Ethics Committee of Iran University of Medical Sciences (Tehran, Iran).

\section{Drugs and chemicals}

Phenobarbital was purchased from Temad Co. (Tehran, Iran). Pilocarpine hydrochloride and scopolamine methyl nitrate were procured from SigmaAldrich (St. Louis, MO, USA). p75 neurotrophic factor antagonist peptide was synthesized and purchased from GenScript, USA, with a minimum $92.9 \%$ purity.

\section{Induction of pilocarpine model of epilepsy}

To induce epilepsy, rats were injected with pilocarpine hydrochloride $(380 \mathrm{mg} / \mathrm{kg}$, i.p.; SigmaAldrich, UK), a muscarinic cholinergic agonist. In order to prevent the peripheral cholinergic effects of pilocarpine, rats were pre-treated with scopolamine methyl nitrate, as a cholinergic antagonist $(1 \mathrm{mg} / \mathrm{kg}$, i.p.; Sigma-Aldrich, UK) 30 minutes before the injection of a single dose of pilocarpine hydrochloride. Then the treated rats were monitored for a period of 3 to 4 hours after injection of pilocarpine, and the seizure severity was graded according to Racine's criteria ${ }^{[33]}$. Only rats were included in the present work if they exhibited stage 4 or 5 seizure score. In order to terminate the sustained seizure that lasted for 3 hours, diazepam (7 $\mathrm{mg} / \mathrm{kg}$, i.p.) was injected, and an additional dose of diazepam ( $3 \mathrm{mg} / \mathrm{kg}$, i.p.) was administered every 2 hours, if needed, and then the animals were cared and fed with Hartmann's solution till recovery ${ }^{[34]}$. Two weeks after pilocarpine injection, the occurrence of spontaneous seizures was recorded during chronic phase using daily video monitoring 8 hours/day for two weeks.

\section{Behavioral assessment}

Excitability and sensory responsiveness of control and pilocarpine-treated rats were evaluated using different behavioral tests, including approach-response, touch-response, finger-snap, and pick-up tests as described by Huang et al. ${ }^{[35]}$. Behavioral assessments were performed two weeks after status epilepticus induction between 9 a.m. and 12.30 p.m. Three groups of epileptic rats were randomly selected for i.p. injection of p75 antagonist alone $(1 \mathrm{mg} / \mathrm{kg}$ dissolved in normal saline; $\mathrm{n}=7$ ) or an injection of phenobarbital alone $(30 \mathrm{mg} / \mathrm{kg}$, dissolved in normal saline; $\mathrm{n}=7)$, or co-administration of p75 antagonist and phenobarbital with 30 minutes interval between injection of phenobarbital and p75 antagonist. All injections and tests were done for six days that were performed in the home cage with 30-min intervals between each test ${ }^{[36]}$.

\section{Approach-response test}

A pen held vertically was moved slowly toward the face of the animal, and responses were scored as 1 , the rat had no reaction; 2 , the rat sniffed at the pen; 3 , the rat moved away from the pen; 4 , the rat was frozen; 5, the rat jumped away from the pen; 6 , the rat jumped at or attacked the pen.

\section{Touch-response test}

The animal was gently prodded in the rump with the blunt end of a pen. Responses were recorded as 1, the rat has no reaction; 2, the rat turned toward the object; 3 , the rat moved away from the object; 4 , the rat frozen; 5 , the rat turned toward the touch; 6 , the rat turned away from the touch; 7 , the rat jumped with or without vocalizations ${ }^{[35,37]}$.

\section{Finger-snap test}

A finger snap several inches above the head of the animal was performed. Responses were scored as 1, the rat had no reaction; 2, the rat jumped slightly (normal reaction); 3 , the rat jumped suddenly ${ }^{[35,38]}$.

\section{Pick-up test}

The animal was picked up by grasping around the body. Responses were scored as 1, very easy; 2, easy with vocalizations; 3 , some difficulties, the rat reared and faced the hand; 4, frozen (the rat); 5, difficult, the rat avoided the hand by moving away; 6 , very difficult, the rat behaved defensively and may attacked the hand $^{[35,37]}$. The behavioral tests were done by three independent observers, and the means of their scores were calculated for each animal for each test.

\section{Video monitoring of behavioral seizure}

To evaluate the frequency and duration of spontaneous recurrent seizures (SRS), the rats were videotaped and then reviewed by an investigator blinded to treatment groups to score the number and cumulative duration of tonic-clonic seizures. Origin 7.5 SR6 (Microcal Software, Northampton, MA, USA) software was used for data recording and analysis. Power spectrum analysis was performed after applying a Hamming window function ${ }^{[39]}$.

\section{Elevated plus maze}

For assessing anxiety-related behavior and agitation, elevated plus maze test was performed in which maze 
was made of black-painted wood with four elevated arms raised by a single central support to a height of 62 $\mathrm{cm}$ above the floor. It was arranged as a cross with two open arms $(45 \times 10 \mathrm{~cm})$ facing each other, and two other arms enclosed by high walls $(45 \times 10 \times 40 \mathrm{~cm})$. The four arms extended from a common central platform $(10 \times 10 \mathrm{~cm})$. Ridges of $0.5 \mathrm{~cm}$ bordering the open arms were added to provide an additional grip. Behavior on the maze was recorded by a video camera mounted above the plus maze apparatus and connected to a monitor and a video tracking, motion analysis and behavior recognition system (EthoVision $®$, Noldus, Wageningen, Netherlands) in a room under lowintensity light $\left(\begin{array}{ll}20 & \mathrm{l} \times\end{array}\right)$. The maze was divided into five areas, one for each arm and one for the centre (central platform). Programming and data recording equipment were controlled by a computer ${ }^{[40]}$.

\section{Real-time RT-PCR analysis of mRNA expression}

The mRNA level p75 and pro-NGF genes in hippocampal tissue were determined in different groups of rats ( $n=4$ for each group). The rats were sacrificed at one week, two weeks, and three weeks after the induction of TLE model by pilocarpine, and then hippocampal tissue was dissected over cold PBS. Briefly, total cellular mRNA was isolated using QIAzol, according to the manufacturer's protocol. The quantity and quality of the isolated RNA was assessed by Spectrophotometery (Ultrospec 2000 UV/VIS spectrophotometer,Pharmacia Biotech, Freiburg, Germany). cDNA was generated from $1 \mu \mathrm{g}$ of total RNA by reverse transcription using the cycle script reverse transcription system (Bioneer, Korea). The mRNA expression levels of p75NTR and pro-NGF and GAPDH were determined by quantitative real-time RT-PCR, using a Rotor-Gene 6000 Real-Time Thermal Cycler (Qiagen, Germany). GAPDH mRNA was used as the internal control. The PCR reactions were set up in a volume of $10 \mu \mathrm{L}$ containing $1 \mu \mathrm{L}$ cDNA, $5 \mu \mathrm{L}$ AccuPower® 2X GreenStar qPCR Master Mix (Bioneer, Korea) and $10 \mathrm{pM}$ of each forward and reverse specific primer. Reaction mode was set at $95^{\circ} \mathrm{C}$ for $10 \mathrm{~min}$, followed by 40 cycles of $95{ }^{\circ} \mathrm{C}$ for $15 \mathrm{~s}$ and $60{ }^{\circ} \mathrm{C}$ for $1 \mathrm{~min}$. Amplification specificity was checked using verifying a single peak in melting curves. All samples and controls were normalized to the reference gene. No template controls and no reverse transcriptase control were included in each PCR run. All assays were carried out three times as independent PCR runs for each cDNA sample. The $\Delta \Delta \mathrm{CT}$ method $^{[41]}$ was used to quantify the amplification-fold difference between groups; each gene expression was normalized with respect to GAPDH mRNA content. To validate the use of $\Delta \Delta \mathrm{CT}$ method, a 5-fold serial dilution was performed on a cDNA sample over a 125 -fold range. For each dilution sample, amplifications were performed in triplicate using reference and target gene primers. The average CT of all tests was calculated, and the $\triangle \mathrm{CT}$ of target (p75NTR anf pro-NGF) and reference (GAPDH) genes were determined. A plot of the log cDNA dilution versus $\Delta \mathrm{CT}$ ( $\Delta \mathrm{CT}$ target- $\Delta \mathrm{CT}$ reference) was made for each target and reference genes, and the slope of fitted line was determined ${ }^{[39]}$.

\section{Statistical analysis}

All statistical analyses were performed using SSPS 19.0 (SPSS Inc., Chicago, IL, USA) and Prism software (version 6.0). Two-way analysis of variance (ANOVA) with Bonferroni's post hoc's test was used to examine significant differences between the groups. All results are presented as mean values \pm standard error of mean (SEM), and $p<0.05$ was considered as statistically significant difference.

\section{RESULTS}

\section{Behavioral changes associated with status epilepticus}

Since p75NTR is up-regulated following induction of $\mathrm{SE}^{[42]}$ and may be involved in several psychiatric diseases $^{[17,25]}$; therefore, we here asked whether the blockage of p75NTR would ameliorate behavioral changes associated with pilocarpine treatment in a rat model of SE. Findings showed that pilocarpine-treated rats exhibited significantly higher scores for aggression and anxiety in the approach and in the touch-response tests. In the approach-response test, the average score in control rats was $2.07 \pm 0.21$ versus $4.59 \pm 0.19$ in the pilocarpine-treated rats $(p<0.001$; Fig. 1A). In the touch-response test, the average score for control rats was $2.11 \pm 0.20$ versus $5.40 \pm 0.34$ in the pilocarpinetreated rats $(p<0.001$; Fig. 1B). Similarly, in the finger-snap test, epileptic rats were more disturbed, showing the higher levels of anxiety and restlessness $(2.52 \pm 0.19)$ as compared to the control rats $(1.42 \pm$ $0.19, p<0.001$; Fig. 1C). In the pick-up test, the mean score was significantly elevated in pilocarpine-treated rats $(4.57 \pm 0.36, p<0.001)$ when compared to control rats $(2.09 \pm 0.20$; Fig. 1D). These results indicated that epileptic rats displayed significantly the increased levels of aggressive behavior compared to the control rats. Next, the effects of p75NTR antagonist treatment alone or in combination with phenobarbital on behavioral responses were investigated. Pilocarpinetreated rats were given daily i.p. injection of p75NTR antagonist alone, phenobarbital alone, or a combination 

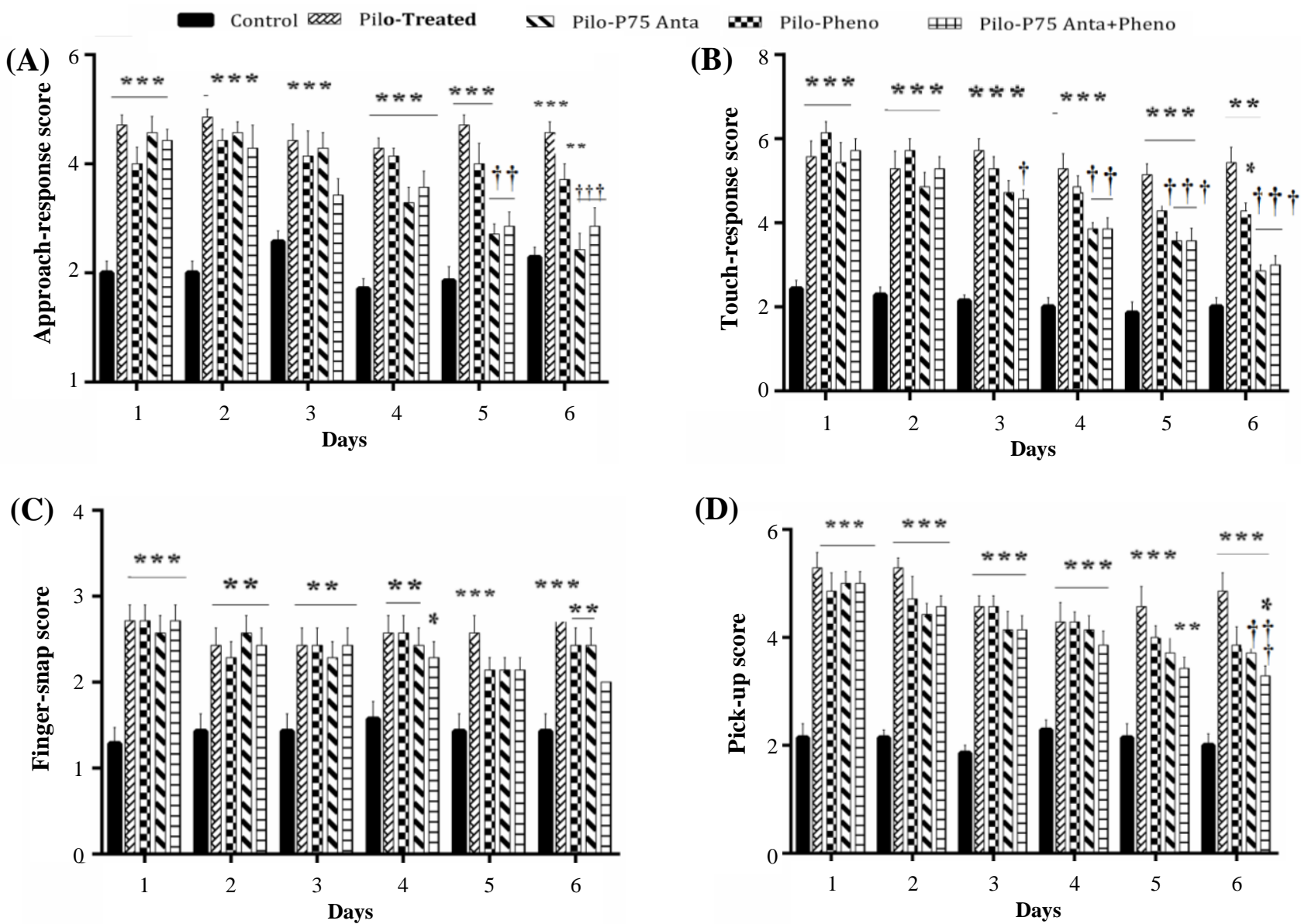

Fig. 1. Behavioral assessment of P75NTR blockage in a rat model of pilocarpine-induced status epilepticus using approach-response (A), touch-response (B), finger-snap (C), and pick-up (D) on six days following SE induction. Bars represent mean \pm SEM of the score. Two-way ANOVA was followed by post hoc comparisons using the Bonferroni's method between control, pilocarpine-treated, pilo + P75 antagonist, pilo + phenobarbital, and pilo + P75 antagonist+phenobarbital. *represents significant difference between all treated groups and the control rats $\left({ }^{*} p<0.05,{ }^{* *} p<0.01,{ }^{* * *} p<0.001\right)$ and $\dagger$ shows significant difference between pilocarpine-treated rats and the control and other treated animals $\left({ }^{\dagger} p<0.05,{ }^{\dagger \dagger} p<0.01\right)$.

of both for six days and then behavioral tests were performed over a period of six days, starting from the second weeks after the induction of SE. The results of the behavioral tests showed that treatment with p75NTR antagonist alone or with phenobarbital improved the behavioral responses in approach resulted in a significant lowered mean scores when compared with pilocarpine-treated alone rats during days 5-6 ( $p<$ 0.001; Fig. 1A). Blockade of p75NTR and treatment with combined p75NTR antagonist and phenobarbital led to a significant decrease in the touch-response score at 5-6 days ( $p<0.001$, Fig. 1B). Phenobarbital treatment alone did not affect the aggressive behavioral scores compared to the epileptic rats (Figs. 1A and 1B). Hypersensitive responses of epileptic rats were also evident both in the finger-snap and pick-up tests (Figs. 1C and 1D), and treatment with p75NTR antagonist alone or in combination with phenobarbital significantly reduced the behavioral hyperexcitability in epileptic rats on days 5 and 6 ( $p<0.001$; Figs. 1C and 1D). However, there were no significant differences between either p75NTR antagonist treatment alone or when co-treated with phenobarbital and control animals in all performed tests.

\section{Duration and frequency of spontaneous recurrent seizures}

Two weeks after SE induction, continuous 20 hours video monitoring was used, and the average of frequency and duration of SRS was investigated following the blockade of p75NTR. The results showed that p75NTR blockade by antagonist injection alone or combined with phenobarbital markedly reduced the frequency and duration of the recurrent seizures, whereas phenobarbital treatment alone had no 
significant effect on either the frequency or duration of SRS (Fig. 2).

\section{Anxiety-related behaviors induced by pilocarpine}

In elevated plus maze test, the open-arm entrance and time spending on the open arms of the maze were considered as a measure of the stress level ${ }^{[43]}$. In the epileptic rats, the percentage of time spent in open arm was significantly longer $(33.88 \pm 3.24 ; p<0.05)$ compared to control rats $(17.8 \pm 2.7$; Fig. $3 \mathrm{~A})$. In addition, a significant increase in the percentage of entries in open arm was observed in the epileptic rats $(35.9 \pm 5.2 ; p<0.05)$ when compared to the controls (20.01 \pm 2.9; Fig. 3B). Treatment with p75NTR antagonist alone or combined with phenobarbital had a significant shortening effect on the percentage of time spent in the open arm compared with pilocarpinetreated alone rats $(18.11 \pm 4.9$ and $19.4 \pm 1.3$, for pilo + p75 antagonist and pilo + p75 antagonist + pheno; $p<$ 0.05; Fig. 3A). However, phenobarbital treatment alone had no significant effect on the time spent in open arm compared with the epileptic rats. Also, the treatment of epileptic rats with p75 antagonist (24.8 \pm
4.9) or phenobarbital alone $(26.04 \pm 1.7)$, but not in combination with phenobarbital (18.39 $\pm 2, p<0.05)$, had no significant effect on the percentage of open arm entries (Fig. 3B) when compared to the epileptic alone rats.

The anxiety ratio, which was calculated by dividing the percentage of time spent in open arm by the percentage of time spent in closed arm, was significantly higher in pilocarpine-treated rats $(0.53 \pm$ 0.07 versus $0.23 \pm 0.04$ in control rats; $p<0.01$; Fig. $3 C)$. In addition, entry ratio (percentage of open arm entry/percentage of closed entry) was significantly higher in epileptic rats $(0.62 \pm 0.12$ versus $0.26 \pm 0.04$ in control group, $p<0.05$; Fig. 3D).

Treatment with phenobarbital or p75 antagonist alone or combined treatment with p75 antagonist and phenobarbital significantly reduced the anxiety ratio $(p<0.05)$. However, only the decreasing effect of combined treatment with P75 antagonist and phenobarbital on entry ratio was statistically significant $(0.23 \pm 0.03, p<0.05$; Fig. 3D), when compared to epileptic rats.
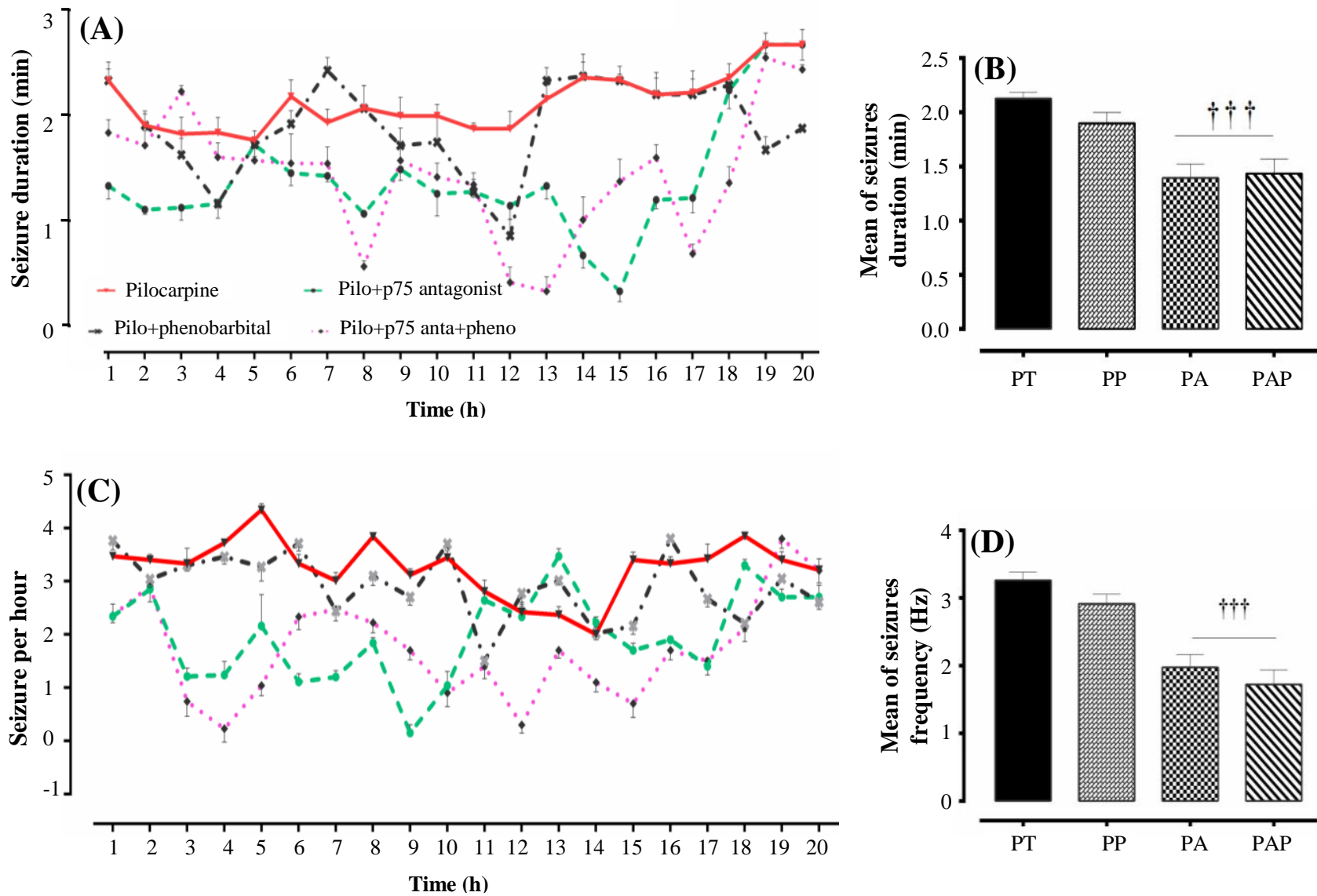

Fig. 2. The results of 20-hour video monitoring of all groups indicating changes in the duration (A) and frequency (C) of spontaneous recurrent seizures. Histograms $(B$ and $D)$ indicate the average $( \pm$ SEM) of duration and frequency of four different experimental groups. PT, pilo-treated; PP, pilo-pheno; PA, pilo-p75 anta; PAP, pilo-p75 anta + pheno 


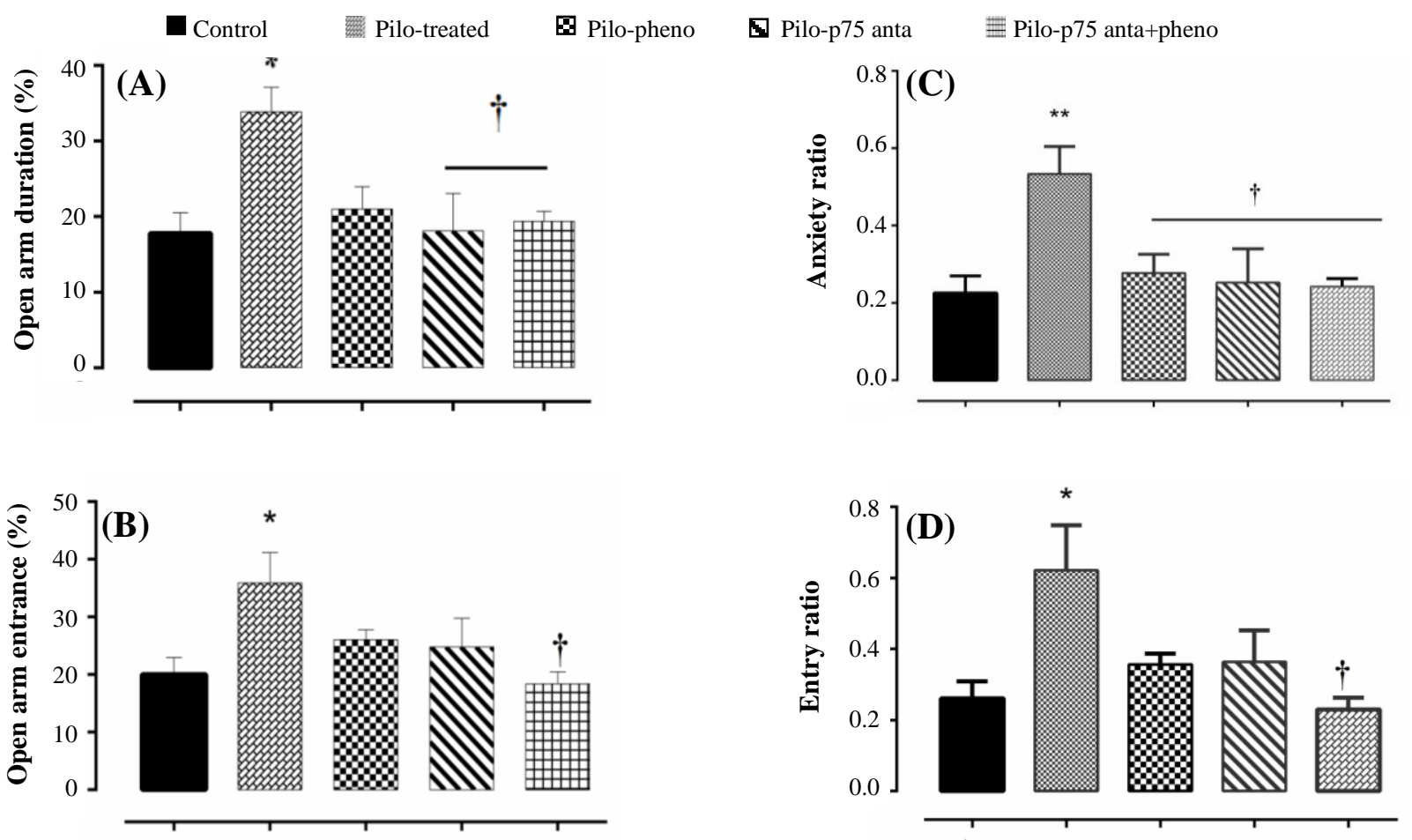

Fig. 3. Anxiety-related behaviors of pilocarpine-treated rats and the controls in the elevated plus-maze test. Behavioral testing was performed two weeks after the SE induction. (A) The percentage of time that the rats spent in the open arm; (B) the percentage of entrance of rats in the aversive open arms of the maze; (C) the anxiety and (D) entry ratios in different experimental conditions. *indicates the statistical difference from the control group $\left({ }^{*} p<0.05 ;{ }^{* * *} p<0.01\right)$ and $\dagger$ shows values different from the epileptic rats.

\section{Changes in mRNA expression of p75NTR and pro- NGF in the hippocampus}

In the present work, the p75 receptor mRNA expression level was examined at one week, two weeks, and three weeks after induction of SE model. The results showed that the p75NTR expression was significantly higher in pilocarpine-induced epileptic model rats compared with that was seen in control group and reached to its highest level $(2.9 \pm 0.1, p<$ 0.001 ) in the first week after the induction of model and then decreased at the second $(2.1 \pm 0.2)$ and the third weeks $(2.07 \pm 0.1)$ after SE induction. However, it was significantly higher than the control rats at all those time points $(1 \pm 0.06$; Fig. $4 \mathrm{~A})$. Next, the proNGF expression was examined after epileptic model induction. Interestingly, a similar expression pattern to the p7NTR was observed for pro-NGF mRNA expression in SE group. Within the first week after the induction of epileptic model, pro-NGF gene expression showed an initial significant increase at the first week $(4.03 \pm 0.2)$ when compared to the control $(1 \pm 0.081)$, and thereafter a decline in the expression was observed at the second $(2.033 \pm 0.08)$ and third $(2.24 \pm 0.1)$ weeks after SE induction (Fig. 4B). However, the expression level was still significantly higher than that of control group.

\section{DISCUSSION}

In line with previous investigations in epileptic rats $^{[22,44-46]}$, we demonstrated here the up-regulation of mRNA expressions of $\mathrm{p} 75 \mathrm{NTR}$ and pro-NGF in a rat pilocarpine-induced SE model, which in turn is associated with the elevated level of aggressive behavior.

Evidence has implied the role of p75NTR receptor and its ligands in the regulation and modulation of neurological and behavioral functions ${ }^{[47-49]}$. Some prior reports have also indicated that epilepsy often shows a comorbidity with behavioral disturbances, including aggression and agitation ${ }^{[12,17,43]}$, and induction of $\mathrm{SE}$ by pilocarpine can also provoke seizure-associated behaviors such as aggressive and unsocial responses. However, the open basis of this coincidence is not fully defined.

The present results indicated that pilocarpineinjected rats displayed less anxiety-like behaviors, 

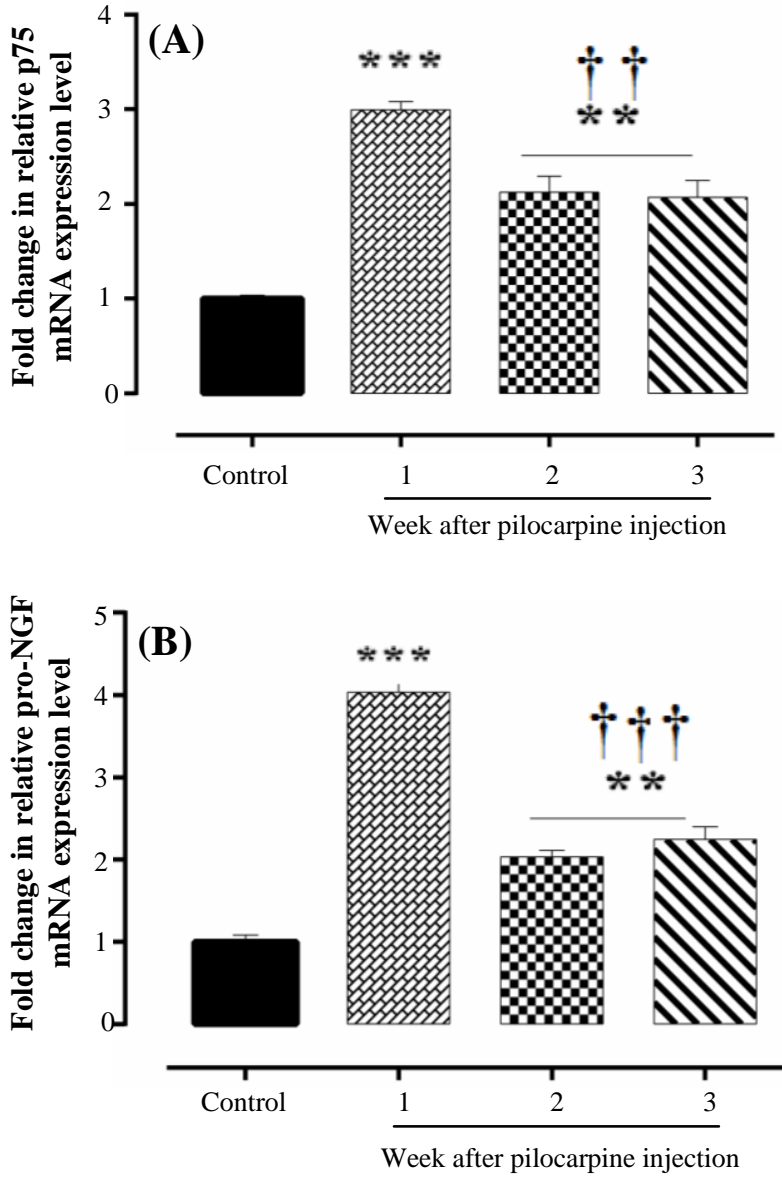

Fig. 4. The levels of mRNA expression of p75NTR and proNGF in the hippocampus of control and pilocapine-treated animals. (A) Data analysis showed significantly increase in p75NTR expression in pilocarpine-induced SE group at one week $\left({ }^{* * *} p<0.001\right)$, two weeks, and three weeks $\left({ }^{* *} p<0.01\right)$ after pilocarpine injection compared to the control group. Its mRNA expression however was decreased at $2^{\text {nd }}$ and $3^{\text {rd }}$ weeks after pilocarpine-injection $\left({ }^{\dagger} p<0.01\right)$ compared to the first week. (B) The pro-NGF mRNA expression was significantly changed at one $\left({ }^{* * *} p<0.001\right)$, two, and three weeks $\left({ }^{* *} p<0.01\right)$ after SE induction compared to the control group. However, its mRNA expression was significantly reduced at $2^{\text {nd }}$ and $3^{\text {rd }}$ weeks, when compared to the first week of SE induction ${ }^{\dagger \dagger \dagger} p<$ 0.001 ). The mRNA expressions of $\mathrm{p} 75 \mathrm{NTR}$ and pro-NGF were normalized to GAPDH and were expressed as mean $\pm \mathrm{SD}, \mathrm{n}=4$.

which is consistent with previous published reports $^{[50-52]}$ that demonstrated SE induction is associated with decreased anxiety in the elevated plusmaze, as evidenced by longer time spent and higher number of entries in arms. Similar to our finding, Detour and colleagues ${ }^{[50]}$ found that in the elevated plus maze, epileptic rats exhibited a significant higher number of entries and the time spent in open arms, suggesting a reduction in the anxiety-related behavior. This reduction has been attributed to the lesions in amygdala and hippocampus ${ }^{[53-55]}$.
Increased expression of $\mathrm{p} 75$ neurotrophin receptor in response to seizure has been reported ${ }^{[44]}$. Increased expression of p75NTR has also been reported in a variety of neurodegenerative diseases, which may be correlated to the cell fate ${ }^{[56]}$. Here, the onset of seizure attacks was paralleled by changes in anxiety-related behavior, possibly due to the up-regulation of mRNA expression of the p75 receptor, which has a role in epilepsy and neuropsychiatric disorders. Epileptic patients suffer more frequently from psychiatric and behavioral disorders than the general population, which have a negative impact on their life quality ${ }^{[6,57,58]}$. Hence, the understanding of underlying mechanism is necessary for introduction of effective treatment strategy for behavioral disorders associated with epilepsy.

Neurotrophins and their receptors have been reported to be involved in epileptogenesis using several animal models of epilepsy ${ }^{[59-61]}$. p75, which is normally expressed during development, has been shown to be re-expressed in adulthood under various pathological conditions, including epilepsy ${ }^{[15,42]}$. In addition, Volosin et al. ${ }^{[44]}$ have suggested a role for proneurotrophins acting through p75NTR in hippocampal cell death after seizure. Several documents have also suggested a pivotal role for neurotrophins and their receptors in various psychiatric disorders such as depression ${ }^{\text {[62-64] }}$.

In the present study, we demonstrated that the upregulation of P75NTR and pro-NGF is associated with behavioral alterations following the induction of SE by pilocarpine, which is consistent with previous studies $^{[35,36]}$. It has been shown that neurotrophin receptors, especially P75NTR, play an important role in epileptogenesis and are up-regulated in the animal model of epilepsy and epileptic patients ${ }^{[65,66]}$. Therefore, we asked whether the blockade of p75 neurotrophin receptor may be a useful therapeutic target for the treatment of behavioral changes associated with epilepsy following SE induction. Our findings for the first time showed that i.p. injection of p75 antagonist $(1 \mathrm{mg} / \mathrm{kg})$, alone or combined with phenobarbital $(30 \mathrm{mg} / \mathrm{kg})$, significantly reduced the duration and the frequency of SRS. Furthermore, the blockade of p75NTR induced anxiogenic behavior in rats, evidenced by the decrease in the time spent in open arms and the decreased anxiety scores and entry ratio when compared with pilocarpine-treated rats in the elevated plus maze. Moreover, p75NTR inhibition attenuated the behavioral hyperexcitability, as indicated by lower scores in approach- and touchresponse as well as finger-snap and pick-up tests.

In summary, our results suggest that the p75NTR blockade attenuates aggressive behavior in epileptic 
rats, suggesting that the overexpression of p75NTR may be a possible mechanism of the development of aggression and seizures; therefore, its inhibition could be a potential therapeutic approach for psychiatric behaviors associated with epilepsy.

\section{ACKNOWLEDGEMENTS}

The support of the present study by Iran University of Medical Sciences (Tehran, Iran) and the Shahid Beheshti University of Medical Sciences (Tehran, Iran) is acknowledged.

CONFLICT OF INTEREST. None declared.

\section{REFERENCES}

1. Lertxundi U, Hernandez R, Medrano J, DomingoEchaburu S, García M, Aguirre C. Antipsychotics and seizures: higher risk with atypicals? Seizure 2013; 22(2): 141-143.

2. Josephson CB, Jette' N. Psychiatric comorbidities in epilepsy. International review of psychiatry 2017; 29(5): 409-424.

3. de Oliveira GN, Kummer A, Salgado JV, Portela EJ, Sousa-Pereira SR, David AS, Teixeira AL. Psychiatric disorders in temporal lobe epilepsy: an overview from a tertiary service in Brazil. Seizure 2010; 19(8): 479-484.

4. de Souza EA, Salgado PC. A psychosocial view of anxiety and depression in epilepsy. Epilepsy and behavior 2006; 8(1): 232-238.

5. Jackson MJ, Turkington D. Depression and anxiety in epilepsy. Journal of neurology, neurosurgery and psychiatry 2005; 76(1): 145-147.

6. Kwon OY, Park SP. Depression and anxiety in people with epilepsy. Journal of clinical neurology 2014; 10(3): 175-188.

7. Engel J Jr. Mesial temporal lobe epilepsy: what have we learned? The neuroscientist 2001; 7(4): 340-352.

8. Kuruba R, Hattiangady B, Shetty AK. Hippocampal neurogenesis and neural stem cells in lobe epilepsy. Epilepsy and behavior 2009; 14(1): 65-73.

9. Cohen I, Navarro V, Clemenceau S, Baulac M, Miles R. On the origin of interictal activity in human temporal lobe epilepsy in vitro. Science 2002; 298(5597): 14181421.

10. Cohen I, Navarro V, Le Duigou C, Miles R. Mesial temporal lobe epilepsy: a pathological replay of developmental mechanisms? Biology of the cell 2003; 95(6): 329-333.

11. Drevets WC, Price JL, Furey ML. Brain structural and functional abnormalities in mood disorders: implications for neurocircuitry models of depression. Brain structure and function 2008; 213(1-2): 93-118.

12. Krishnakumar A, Nandhu MS, Paulose CS. Upregulation of 5-HT $2 \mathrm{C}$ receptors in hippocampus of pilocarpine-induced epileptic rats: Antagonism by Bacopa monnieri. Epilepsy and behavior 2009; 16(2): 225-230.

13. Kandratavicius L, Monteiro MR, Assirati Jr JA, Carlotti Jr CG, Hallak JE, Leite JP. Neurotrophins in mesial temporal lobe epilepsy with and without psychiatric comorbidities. Journal of neuropathology and experimental neurology 2013; 72(11): 1029-1042.

14. Kandratavicius L, Hallak JE, Carlotti CG, Assirati JA, Leite JP. Hippocampal expression of heat shock proteins in mesial temporal lobe epilepsy with psychiatric comorbidities and their relation to seizure outcome. Epilepsia 2014; 55(11): 1834-1843.

15. Dechant G, Barde YA. The neurotrophin receptor p $75^{\mathrm{NTR}}$ : novel functions and implications for diseases of the nervous system. Nature neuroscience 2002; 5(11): 1131-1136.

16. Burke MA, Bothwell M. p75 Neurotrophin receptor mediates neurotrophin activation of NF-kappa B and induction of iNOS expression in P19 neurons. Journal of neurobiology 2003; 55(2): 191-203.

17. Fujii T, Kunugi H. p75NTR as a therapeutic target for neuropsychiatric diseases. Current molecular pharmacology 2009; 2(1): 70-76.

18. Bernabeu RO, Longo FM. The p75 neurotrophin receptor is expressed by adult mouse dentate progenitor cells and regulates neuronal and non-neuronal cell genesis. BMC neuroscience 2010; 11: 136.

19. Mobley WC, Woo JE, Edwards RH, Riopelle RJ, Longo FM, Weskamp G, Otten U, Valletta Js, Johnston MV. Developmental regulation of nerve growth factor and its receptor in the rat caudate-putamen. Neurone 1989; 3(5):655-64.

20. Cragnolini AB, Huang $\mathrm{Y}$, Gokina $\mathrm{P}$, Friedman WJ. Nerve growth factor attenuates proliferation of astrocytes via the p75 neurotrophin receptor. Glia 2009; 57(13): 1386-1392.

21. Troy CM, Friedman JE, Friedman WJ. Mechanisms of p75-mediated death of hippocampal neurones role of caspases. Journal of biological chemistry 2002; 277(37): 34295-34302.

22. Roux PP, Colicos MA, Barker PA, Kennedy TE. p75 neurotrophin receptor expression is induced in apoptotic neurones after seizure. Journal of neuroscience 1999; 19(16): 6887-6896.

23. Ernfors $\mathrm{P}$, Lindefors $\mathrm{N}$, Chan-Palay V, Persson $\mathrm{H}$. Cholinergic neurones of the nucleus basalis express elevated levels of nerve growth factor receptor mRNA in senile dementia of the Alzheimer type. Dementia and geriatric cognitive disorders 1990;1(3):138-45.

24. Ibáñez CF, Simi A. p75 neurotrophin receptor signaling in nervous system injury and degeneration: paradox and opportunity. Trends in neurosciences 2012; 35(7): 431440.

25. Kunugi H, Hashimoto R, Yoshida M, Tatsumi M, Kamijima K. A missense polymorphism (S205L) of the lower affinity neurotrophin receptor p75NTR gene is associated with depressive disorder and attempted suicide. American journal of medical genetics part $B$ 2004; 129B(1): 44-46. 
26. McGregor S, Strauss J, Bulgin N, De Luca V, George CJ, Kovacs M, Kennedy JL. p75NTR gene and suicide attempts in young adults with a history of childhood onset mood disorder. American Journal of Medical Genetics Part B 2007; 144(5): 696-700.

27. Curia G, Longo D, Biagini G, Roland SGJ, Avoli M. The pilocarpine model of temporal lobe epilepsy. Journal of neuroscience methods 2008; 172(2-4): 143157.

28. Scorza FA, Arida RM, Naffah-Mazzacoratti MdGa, Scerni DbA, Calderazzo L, Cavalheiro EA. The pilocarpine model of epilepsy: what have we learned? Anais da Academia Brasileira de Ciencias 2009; 81(3): 345-365.

29. Löscher W, Hirsch LJ, Schmidt D. The enigma of the latent period in the development of symptomatic acquired epilepsy- traditional view versus new concepts. Epilepsy and behavior 2015; 52 (Pt A): 78-92.

30. Lopes MW, Lopes SC, Santos DbB, Costa AP, Gonalves FM, de Mello N, Prediger RD, Farina M, Walz R, Leal RB. Time course evaluation of behavioral impairments in the pilocarpine model of epilepsy. Epilepsy and behavior 2016; 55: 92-100.

31. Turner BJ, Murray SS, Piccenna LG, Lopes EC, Kilpatrick TJ, Cheema SS. Effect of p75 neurotrophin receptor antagonist on disease progression in transgenic amyotrophic lateral sclerosis mice. Journal of neuroscience research 2004; 78(2): 193-199.

32. Delbary-Gossart S, Lee S, Baroni M, Lamarche I, Arnone M, Canolle B, Lin A, Sacramento J, Salegio EA, Castel MN, Delesque-Touchard N, Alam A, Laboudie P, Ferzaz B, Savi P, Herbert JM, Manley GT, Ferguson AR, Bresnahan JC, Bono F, Beattie MS. A novel inhibitor of p75-neurotrophin receptor improves functional outcomes in two models of traumatic brain injury. Brain 2016; 139(6): 1762-1782.

33. Racine RJ. Modification of seizure activity by electrical stimulation: II. Motor seizure. Electroencephalography and clinical neurophysiology 1972; 32(3): 281-294.

34. Le AP, Friedman WJ. Matrix metalloproteinase-7 regulates cleavage of pro-nerve growth factor and is neuroprotective following kainic acid-induced seizures. Journal of neuroscience 2012; 32(2): 703-712.

35. Huang X, McMahon J, Huang Y. Rapamycin attenuates aggressive behavior in a rat model of pilocarpineinduced epilepsy. Neuroscience 2012; 215: 90-97.

36. Rice AC, Floyd CL, Lyeth BG, Hamm RJ, DeLorenzo RJ. Status Epilepticus Causes Long Term NMDA Receptor Dependent Behavioral Changes and Cognitive Deficits. Epilepsia 1998; 39(11): 1148-1157.

37. Bröer S, Zolkowska D, Gernert M, Rogawski MA. Proconvulsant actions of intrahippocampal botulinum neurotoxin B in the rat. Neuroscience 2013; 12(252): 253-261.

38. Eftekhari S, Mehrabi S, Soleimani M, Hassanzadeh G, Rahmanzadeh R, Hadjighassem MR, Joghataei MT. BDNF modifies hippocampal KCC2 and NKCC1 expression in a temporal lobe epilepsy model. Acta neurobiologiae experimentalis 2017; 74(3): 276-287.
39. Dzhala VI, Brumback AC, Staley KJ. Bumetanide enhances phenobarbital efficacy in a neonatal seizure model. Annals of neurology 2008; 63(2): 222-235.

40. Groticke I, Hoffmann K, Löscher W. Behavioral alterations in the pilocarpine model of temporal lobe epilepsy in mice. Experimental neurology 2007; 207(2): 329-349.

41. Livak KJ, Schmittgen TD. Analysis of relative gene expression data using real-time quantitative PCR and the 2(- $\Delta \Delta \mathrm{C}(\mathrm{T})$ method. Methods 2001; 25(4): 402-408.

42. VonDran MW, LaFrancois J, Padow VA, Friedman WJ, Scharfman HE, Milner TA, Hempstead BL. p75NTR, but not proNGF, is upregulated following status epilepticus in mice. ASN neuro 2014; 6(5).

43. Brandt C, Gastens AM, Zhen Sun M, Hausknecht M, Löscher W. Treatment with valproate after status epilepticus: effect on neuronal damage, epileptogenesis, and behavioral alterations in rats. Neuropharmacology 2006; 51(4): 789-804.

44. Volosin M, Trotter C, Cragnolini A, Kenchappa RS, Light M, Hempstead BL, Carter BD, Friedman WJ. Induction of proneurotrophins and activation of p75NTR-mediated apoptosis via neurotrophin receptorinteracting factor in hippocampal neuroneneuronals after seizures. Journal of neuroscience 2008; 28(39): 9870-9879.

45. Grabenstatter HL, Carlsen J, Raol YH, Yang T, Hund D, Cruz Del Angel Y, White AM, Gonzalez MI, Longo FM, Russek SJ, Brooks-Kayal AR. Acute administration of the small molecule p75(NTR) ligand does not prevent hippocampal neuron loss or development of spontaneous seizures after pilocarpine induced status epilepticus. Journal of neuroscience research 2014; 92(10): 1307-1318.

46. Thomas AX, Del Angel YC, Gonzalez MI, Carrel AJ, Carlsen J, Lam PM, Hempstead BL, Russek SJ, BrooksKayal AR. Rapid increases in proBDNF after pilocarpine-induced status epilepticus in mice are associated with reduced proBDNF cleavage machinery. eNeuro 2016; 3(1).

47. Buckley PF, Mahadik S, Pillai A, Terry A. Neurotrophins and schizophrenia. Schizophrenia research 2007; 94(1-3): 1-11.

48. Schulte-Herbrüggen O, Braun A, Rochlitzer S, JockersScherubl MC, Hellweg R. Neurotrophic factors-a tool for therapeutic strategies in neurological, neuropsychiatric and neuroimmunological diseases? Current medicinal chemistry 2007; 14(22): 2318-2329.

49. Davies AM. Nerve growth factor synthesis and nerve growth factor receptor expression in neural development. International review of cytology 1991; 128: $109-138$.

50. Detour J, Schroeder H, Desor D, Nehlig A. A 5-month period of epilepsy impairs spatial memory, decreases anxiety, but spares object recognition in the lithiumpilocarpine model in adult rats. Epilepsia 2005; 46(4): 499-508.

51. Inostroza M, Cid E, Brotons-Mas J, Gal B, Aivar P, Uzcategui YG, Sandi C, de la Prida LM. Hippocampaldependent spatial memory in the water maze is 
preserved in an experimental model of temporal lobe epilepsy in rats. PLoS one 2011; 6(7): e22372.

52. Faure JB, Akimana G, Carneiro JEM, Cosquer B, Ferrandon A, Geiger K, Koning E, Penazzi Ln, Cassel J, Nehlig A. A comprehensive behavioral evaluation in the lithium-pilocarpine model in rats: effects of carisbamate administration during status epilepticus. Epilepsia 2013; 54(7): 1203-1213.

53. Davis M. The role of the amygdala in fear and anxiety. Annual review of neuroscience 1992; 15(1): 353-375.

54. Bannerman DM, Rawlins JNP, McHugh SB, Deacon RMJ, Yee BK, Bast T, Zhang WN, Pothuizen HHJ, Feldon J. Regional dissociations within the hippocampus memory and anxiety. Neuroscience and biobehavioral reviews 2004; 28(3): 273-283.

55. Korn CW, Vunder J, Mir Jl, Fuentemilla Ls, Hurlemann $\mathrm{R}$, Bach DR. Amygdala lesions reduce anxiety-like behavior in a human benzodiazepine-sensitive approach-avoidance conflict test. Biological Psychiatry 2017; 82(7): 522-531.

56. Meeker R, Williams K. Dynamic nature of the p75 neurotrophin receptor in response to injury and disease. Journal of neuroimmune pharmacology 2014; 9(5): 615628.

57. Muller CJ, Gruticke I, Bankstahl M, Luscher W. Behavioral and cognitive alterations, spontaneous seizures, and neuropathology developing after a pilocarpine-induced status epilepticus in C57BL/6 mice. Experimental neurology 2009; 219(1): 284-297.

58. Izci F, Findikli E, Zincir S, Camkurt A, Kizilkurt O, Giynas F, Korkmaz S, Akin EB. Psychiatric Evaluation of Organ Donor Candidates in a University Hospital and Their Anxiety, Depression and Quality of Life Levels/Bir niversite hastanesine basvuran organ nakli verici adaylarinin psikiyatrik degerlendirmeleri, anksiyete, depresyon ve yasam kalitesi düzeyleri. Dusunen Adam. 2017; 30(1): 48-56.

59. Koshimizu H, Kiyosue K, Hara T, Hazama S, Suzuki S, Uegaki K, Nagappan G, Zaitsev E, Hirokawa T, Tatsu
Y, Ogura A, Lu B, Kojima M. Multiple functions of precursor BDNF to CNS neurons: negative regulation of neurite growth, spine formation and cell survival. Molecular brain 2009; 2: 27.

60. Friedman WJ. Proneurotrophins, seizures, and neuronal apoptosis. Neuroscientist 2010; 16(3): 244-252.

61. McNamara JO, Scharfman HE. Temporal lobe epilepsy and the BDNF receptor, TrkB. In: Noebels JL, Avoli M, Rogawski MA, Olsen RW, Delgado-Escueta AV, editors. Jasper's Basic Mechanisms of the Epilepsies. Bethesda, MD: National Center for Biotechnology Information (US); 2012.

62. Kerman IA. New insights into BDNF signaling: relevance to major depression and antidepressant action. American journal of psychiatry 2012; 169(11): 11371140.

63. Olsen D, Kaas M, Schwartz O, Nykjaer A, Glerup S. Loss of BDNF or its receptors in three mouse models has unpredictable consequences for anxiety and fear acquisition. Learning and memory 2013; 20(9): 499504.

64. Andero R, Choi DC, Ressler KJ. BDNF-TrkB receptor regulation of distributed adult neural plasticity, memory formation, and psychiatric disorders. Progress in molecular biology and translational science 2014; 122: 169-192.

65. Shetty AK, Zaman V, Shetty GA. Hippocampal neurotrophin levels in a kainate model of temporal lobe epilepsy: a lack of correlation between brain-derived neurotrophic factor content and progression of aberrant dentate mossy fiber sprouting. Journal of neurochemistry 2003; 87(1): 147-159.

66. Liu G, Gu B, He XP, Joshi RB, Wackerle HD, Rodriguiz RM, Wetsel WC, McNamara JO. Transient inhibition of TrkB kinase after status epilepticus prevents development of temporal lobe epilepsy. Neuron 2013; 79(1): 31-38. 